\title{
Incisional Negative Pressure Wound Therapy Dressing in Total Joint Arthroplasty: what is the evidence? A Meta-Analysis
}

\author{
Wen-Xing Wei \\ Sichuan University West China Hospital \\ Yi Zeng \\ Sichuan University West China Hospital \\ Yuan Liu \\ Sichuan University West China Hospital \\ Ming-Yang Li \\ Sichuan University West China Hospital \\ Yuan-gang Wu \\ Sichuan University West China Hospital \\ Bin Shen ( $\square$ shenbin_1971@163.com ) \\ West China Hospital, Sichuan University https://orcid.org/0000-0002-9632-7221
}

Research article

Keywords: incisional negative pressure wound therapy dressing, total knee arthroplasty, total hip arthroplasty

Posted Date: January 15th, 2020

DOI: https://doi.org/10.21203/rs.2.20951/v1

License: (c) This work is licensed under a Creative Commons Attribution 4.0 International License. Read Full License 


\section{Abstract}

Background

The purpose of this study is to evaluate whether incisional negative pressure therapy dressing (iNPWT) has an advantage over conventional wound dressing (CWD) on wound healing for patients with total joint arthroplasty (TJA)

Methods

We searched the electronic databases including PubMed, The Cochrane Library, EMBASE via Ovid SP, Medline via Ovid SP, to screening published randomized controlled trials and high-quality cohort studies reported that incisional negative pressure therapy dressing applied in hip and knee arthroplasty. We analyzed the overall complications, major and minor complications, dressing changes, infection rate, and the rate of reoperation. The relevant data was analyzed by RevMan5.3.

Results

Six studies met our criteria, and included 1405 incisions in 971 participants with total joint arthroplasty which were randomized either to incisional negative pressure therapy dressing group $(n=578)$ or to conventional wound dressing group $(n=827)$. The risk for developing a minor complication between two groups was not significantly different (risk ratio [RR] 0.58, $p=0.40$ ) and for major complication was also not significantly different (RR $0.71, p=0.39)$. In terms of dressing changes, the iNPWT was fewer than the control group $(P<0.05)$. The effect of rate of infection and reoperation was not significantly different (RR $0.65, p=0.27)$.

Conclusions

For patients underwent TJA, applying iNPWT may be associated with fewer dressing change, which maybe mean less exudation. There was no significant difference on the rate of infection and reoperation, and experiencing either minor or major complications between participants in whom iNPWT versus CWD were used for wound. However, more high-quality randomized or non-randomized controlled trials with larger sample sizes and cost-effectiveness analysis are required.

\section{Background}

Total joint arthroplasty (TJA) including TKA and THA are currently the most common surgical procedures for severe knee and hip diseases and the incidence continues to increase annually[1]. Despite the advances in preoperative preparation, surgical techniques and postoperative care, however, often, there are some factors making the management of surgical wound challenging because of the high risk of developing complications. Importantly, the further sequelae may cause in additional surgical procedures or revisions, extension of the length of stay and an increasing economic burden substantially. Therefore, it is critical to avoid wound complications for the success of TJA.

National clinic guidelines recommend that incisions are covered with a postoperative cover dressing to help control postoperative bleeding, absorb drainage and provide mechanical protection [2]. Traditionally, conventional gauze wound dressing is regarded as postsurgical standard care. However, with higher attention to surgical wound healing, various new cover dressings emerged. Incisional negative pressure wound therapy dressing (iNPWT) has been a successful manner of wound healing management which is widely used in several surgical fields [3]. It is thought to contribute to the healing process through a number of mechanisms, including decreasing exudate, increasing blood flow, stabilization of the environment, stimulation of angiogenesis, and modulation of inflammation et al [48]. Although numerous studies compared the effect between iNPWT and conventional wound dressing, the preference among them remains controversial. Some study investigated that the use of iNPWT could reduce overall incidence of complications after TJA in a comprehensive patient population [9]. However, other studies demonstrated that there were not a benefit to the use of iNPWT after TJA $[10,11]$.

This is the first study that assessing the effect of iNPWT on wound healing in TJA systematically. The purpose of our study is to analyze the included studies to compare (1) the rate of overall, minor and major complications, (2) the rate of infection, (3) the rate of reoperation, and (4) difference in dressing change between iNPWT and CWD in TJA.

\section{Methods}


The methods we used were based on the recommended PRISMA checklist guidelines [12]. This study was a meta-analysis, so there were no conflict of interests and ethical approval.

\subsection{Search Strategy}

We searched relevant studies by June 3rd, 2019 in the following databases: PubMed, Medline via Ovid SP, EMBASE via Ovid SP, and The Cochrane Library. Only English language publications were included in our meta-analysis. Search strategy we adopted in above databases as follows: (Negative-Pressure Wound Therapy OR negative pressure wound therapy OR vacuum assisted closure OR topical negative pressure therapy) AND (total knee arthroplasty OR total hip arthroplasty OR total knee replacement OR total hip replacement OR TKA OR THA OR TKR OR THR).

\subsection{Outcome Measures}

The primary outcomes in this study were complications including overall, minor and major complications, dressing changes. Furthermore, we also took the rate of infection and reoperation as the secondary outcomes between the two groups. For complications, we defined it as minor (blisters, superficial infection, exudation, hematoma, seroma, swelling, or other) or major (deep infection, wound dehiscence) for each individual study[13].

\subsection{Criteria for Including Studies}

The included studies met PICOS (patients, intervention, comparator, outcome, study design) criteria. These criteria were as follows: (1) Participants received TKA or THA; (2) The intervention was applying iNPWT for TJA; (3) The comparator was applying CWD for TJA; (4) The outcomes of included studies with adequate reported data; (5) The study designs were randomized controlled trials (RCTs) or prospective cohort studies (PCS).

\subsection{Data Extraction}

Two reviewers screened the studies independently. Initially, titles and abstracts were assessed to search potential studies, then obtaining and screening the full text of potentially relevant publications. Once there were any disparities, we resolved it by discussion. A third author was consulted if necessary.

Two authors independently extracted outcomes of the eligibility studies in pre-designed data collection form. The following information and data were extracted: study characteristics included first author, year of publication, settings and participants characteristics (such as age, sex, BMI, surgery type); study design characteristics included method of randomization, blinding, assessment of selective reporting; incomplete data and funding sources; outcomes included definition of outcomes and numerical data. Any discrepancy was resolved by a third author.

\subsection{Assessment of Risk of Bias in Included Studies}

The quality of included studies was assessed independently by 2 authors. We made risk of bias judgment based on tools described in the Cochrane Handbook [14]. Seven domains included random sequence generation, allocation concealment, blinding of participants and personnel, blinding of outcome assessment, incomplete outcome data, selective reporting and other bias were considered to be an evaluation indicator. The overall risk of bias in included trials was evaluated as low risk of bias, high risk of bias and unclear risk of bias. Additionally, we used Jadad scales to evaluate the risk of bias for RCTs. For prospective cohort studies, we assessed the risk of bias by Newcastle-Ottawa scale. The study was assessed as high quality when the Jadad score was more than 4 points. As for Newcastle-Ottawa scale, a high quality study obtained a score of more than 5 points $[15,16]$.

\subsection{Data Synthesis}

The statistical analysis of overall included studies was performed by RevMan5.3 (Cochrane Collaboration). We used risk ratios (RR) and its $95 \%$ confidence interval $(\mathrm{Cl})$ to measure the dichotomous outcome data, such as occurrence of complication and infection et al. For continuous outcome data such as the number of dressing change, we used the measure of mean differences (MD) and its $95 \%$ confidence interval $(\mathrm{Cl})$. Heterogeneity in synthetic results was usually caused by clinical and methodological heterogeneity. We used the chi-squared test and $\mathrm{I}^{2}$ statistic to assess statistical heterogeneity. According to statistical heterogeneity, we selected the fixedeffects model if the $\mathrm{I}^{2}$ estimated $\leq 50 \%$ accompanied by a statistically significant chi-squared $(P<0.1)$. When there was heterogeneity, we sought the sources of it. If the source was ascertained, we intended to perform further subgroup analysis. Otherwise, we analyzed the data in a random-effects model. 


\section{Results}

\subsection{Literature Screening}

The literature search initially identified 135 studies. 68 studies were screened after removing the duplicates and 54 studies were excluded by screening the titles and abstracts. Eight of 14 full-text articles were excluded through careful check. Two studies were excluded due to inadequate outcome reporting. One study was not eligible because of not comparing iNPWT with conventional wound dressing. 5 studies were not completed and published. Finally, 6 studies were included in this study (Fig. 1). Among them, there were 5 RCTs and 1 prospective cohort study.

\subsection{Study Characteristics}

Six studies with 1405 incisions in 971 participants with total joint arthroplasty were included [9, 10, 17-20]. Howell et al [18], investigated 51 patients underwent 60 TKA surgeries. Manoharan et al [10], reported not all participants randomized allocated. Twentyone patients with 42 postoperative knee randomized into two group. The included participants' type of surgery was as followed: TKA, THA. All studies compared incisional negative pressure wound therapy dressing with conventional wound dressing. The age of most of participants $>45$ years old (average age range: $66-80$ years old). The BMl of most of participants $>27 \mathrm{~kg} / \mathrm{cm}^{2}$. The details of study characteristics were shown in Table 1. 
Table 1

\begin{tabular}{|c|c|c|c|c|c|c|c|c|c|}
\hline \multirow[t]{2}{*}{ Study ID } & \multicolumn{5}{|l|}{ Participants } & \multirow{2}{*}{$\begin{array}{l}\text { Intervention } \\
\text { (I/C) }\end{array}$} & \multirow{2}{*}{$\begin{array}{l}\text { Reference } \\
\text { type }\end{array}$} & \multirow[t]{2}{*}{ QAS } & \multirow[t]{2}{*}{ Outcomes } \\
\hline & $\begin{array}{l}\mathrm{N} \\
(\mathrm{I} / \mathrm{C})\end{array}$ & $\begin{array}{l}\text { Age } \\
\text { (years) } \\
(\mathrm{I} / \mathrm{C})\end{array}$ & $\begin{array}{l}\text { Sex } \\
(M / F)\end{array}$ & $\begin{array}{l}\text { BMI } \\
\left(\mathrm{kg} / \mathrm{cm}^{2}\right) \\
(\mathrm{l} / \mathrm{C})\end{array}$ & $\begin{array}{l}\text { Type of } \\
\text { surgery }\end{array}$ & & & & \\
\hline $\begin{array}{l}\text { Giannini } \\
2018 \text { [17] }\end{array}$ & $\begin{array}{l}100 \\
(50 / 50)\end{array}$ & $66.0 / 66.8$ & $37 / 63$ & $27.7 / 28.2$ & $\begin{array}{l}\text { Revision } \\
\text { THA or } \\
\text { TKA }\end{array}$ & iNPWTa/CWD & RCT & 4 & $\begin{array}{l}\text { ASEPSIS } \\
\text { score, Blisters, } \\
\text { VAS, Dressing } \\
\text { changes }\end{array}$ \\
\hline $\begin{array}{l}\text { Howell } \\
2011 \text { [18] }\end{array}$ & $\begin{array}{l}60 \\
(24 / 36)\end{array}$ & Unclear & Unclear & $>30$ & TKA & iNPWT ${ }^{\mathrm{b}} / \mathrm{CWD}$ & $\mathrm{RCT}$ & 6 & $\begin{array}{l}\text { Infection rate, } \\
\text { Blisters, }\end{array}$ \\
\hline $\begin{array}{l}\text { Karlakki } \\
2016[19]\end{array}$ & $\begin{array}{l}209 \\
(102 / 107)\end{array}$ & $69.0 / 69.2$ & $104 / 105$ & $30.1 / 28.4$ & $\begin{array}{l}\text { THA or } \\
\text { TKA }\end{array}$ & iNPWT/CWD & RCT & 5 & $\begin{array}{l}\text { Length of } \\
\text { stay, Wound } \\
\text { complications, } \\
\text { Dressing } \\
\text { changes, Cost- } \\
\text { effectiveness }\end{array}$ \\
\hline $\begin{array}{l}\text { Keeney } \\
2019[20]\end{array}$ & $\begin{array}{l}398 \\
(185 / 213)\end{array}$ & $\begin{array}{l}60.6 / \\
60.5\end{array}$ & $164 / 234$ & $\begin{array}{l}34.6 / \\
36.5\end{array}$ & $\begin{array}{l}\text { THA or } \\
\text { TKA }\end{array}$ & iNPWTa/CWD & $\mathrm{RCT}$ & 4 & $\begin{array}{l}\text { VAS, Wound } \\
\text { complications, } \\
\text { Wound } \\
\text { drainage, } \\
\text { Late infection } \\
\text { rate }\end{array}$ \\
\hline $\begin{array}{l}\text { Manoharan } \\
2016 \text { [10] }\end{array}$ & $\begin{array}{l}42 \\
(21 / 21)\end{array}$ & Unclear & $19 / 14$ & Unclear & TKA & iNPWT ${ }^{\mathrm{b}} / \mathrm{CWD}$ & $\mathrm{RCT}$ & 6 & $\begin{array}{l}\text { Cost of } \\
\text { dressings, } \\
\text { Wound } \\
\text { complications, } \\
\text { QoL factors, } \\
\text { Maceration, } \\
\text { Blisters. }\end{array}$ \\
\hline $\begin{array}{l}\text { Redfern } \\
2017 \text { [9] }\end{array}$ & $\begin{array}{l}596 \\
(196 / 400)\end{array}$ & $66.9 / 66.8$ & $251 / 345$ & $30.5 / 30.9$ & $\begin{array}{l}\text { THA or } \\
\text { TKA }\end{array}$ & iNPWT/CWD & PCS & 7 & $\begin{array}{l}\text { Wound } \\
\text { complications, } \\
\text { Infection rate }\end{array}$ \\
\hline \multicolumn{10}{|c|}{ The detailed study characteristics of included trials } \\
\hline \multicolumn{10}{|c|}{$\begin{array}{l}\text { N, the number of incisions; I, intervention group; C, control group; BMI, body mass index; iNPWT, incisional negative pressure wound } \\
\text { therapy dressing; CWD, conventional wound dressing; TKA, total knee arthroplasty; THA, total hip arthroplasty; RCT, randomized } \\
\text { controlled trials; PCS, prospective cohort studies; ASEPSIS, additional treatment, the presence of serous discharge, erythema, } \\
\text { purulent exudate, and separation of the deep tissues, the isolation of bacteria, and the duration of inpatient stay; VAS, visual } \\
\text { analogue score; QoL, quality of life. }\end{array}$} \\
\hline
\end{tabular}

\subsection{Risk of Bias}

Three studies of the 5 included studies $[10,18,19]$ performing adequate method of randomization and allocation concealment were considered as low risk of bias. The randomization and allocation concealment were using sealed opaque envelopes or an online computer software. Another 2 studies [17, 20] did not state the randomization. One study [17] reported that a single-blind method was used. One trial [19] reported that used non-blind method. Another 3 studies $[10,18,20]$ did not report blinding procedures. But we were inclined to think that the patients and outcome estimator were not blinded, which did not influence the outcome evaluation because of objective measurements. That one study [18] reported incomplete outcome data resulted from stopped prematurely due to complications, so it was considered as high risk of bias due to selective reporting. The risk of bias assessment of included studies was shown in Fig. 2. Publication bias was assessed by funnel plot diagram (Fig. 3). The funnel plot diagrams of overall complications, minor and major complications, the rate of infection and reoperation were symmetrical, which indicated a low risk of publication bias. We failed to evaluate the risk of publication bias of the number of dressing changes due to only 2 studies reported it.

\subsection{Outcome Measures}

\subsubsection{Overall complications}


The various complications reported by these original studies included blistering, exudate, superficial and deep surgical site infection et al. Result from this meta-analysis supported that there was no significant difference in rate of overall complications between iNPWT group and control group ( $\mathrm{RR}=0.90,95 \% \mathrm{Cl} 0.32-2.57, \mathrm{p}=0.53$, Fig. 4).

\subsubsection{Minor and major complications}

The detail of minor and major complications was shown in Table 2. In terms of minor complications, there was no significant difference between 2 groups $(\mathrm{OR}=0.58,95 \% \mathrm{Cl} 0.13-2.61, \mathrm{p}=0.48$; Fig. 5). Similarly, in terms of major complications, result from this study demonstrated that there was no significant difference between 2 groups $(\mathrm{OR}=0.71,95 \% \mathrm{Cl} 0.33-1.53, \mathrm{p}=0.38$; Fig. 6).

Table 2 Complications

\begin{tabular}{|c|c|c|c|c|c|c|c|}
\hline & \multirow[t]{2}{*}{ Study ID } & \multicolumn{3}{|l|}{ Minor } & \multicolumn{2}{|l|}{ Major } & \multirow{2}{*}{$\begin{array}{l}\text { Total participants with } \\
\text { complications }\end{array}$} \\
\hline & & Blisters & $\begin{array}{l}\text { Superficial } \\
\text { infections }\end{array}$ & $\begin{array}{l}\text { Minor, } \\
\text { other }\end{array}$ & $\begin{array}{l}\text { Deep } \\
\text { infections }\end{array}$ & $\begin{array}{l}\text { Major, } \\
\text { other }\end{array}$ & \\
\hline \multirow[t]{6}{*}{$\begin{array}{l}\text { iNPWT } \\
\text { group }\end{array}$} & $\begin{array}{l}\text { Giannini } 2018 \\
{[17]}\end{array}$ & 6 & 0 & 0 & 0 & 0 & 6 \\
\hline & $\begin{array}{l}\text { Howell } 2011 \\
\text { [18] }\end{array}$ & 15 & 0 & 0 & 1 & 0 & 15 \\
\hline & $\begin{array}{l}\text { Karlakki } 2016 \\
\text { [19] }\end{array}$ & 0 & 0 & 2 & 0 & 0 & 2 \\
\hline & $\begin{array}{l}\text { Keeney } 2019 \\
\text { [20] }\end{array}$ & 0 & 1 & 15 & 6 & 0 & 22 \\
\hline & $\begin{array}{l}\text { Manoharan } \\
2016[10]\end{array}$ & 1 & 0 & 0 & 0 & 0 & 1 \\
\hline & $\begin{array}{l}\text { Redfern } 2017 \\
\text { [9] }\end{array}$ & 0 & 0 & 0 & 2 & 1 & 3 \\
\hline \multirow[t]{6}{*}{$\begin{array}{l}\text { Control } \\
\text { group }\end{array}$} & $\begin{array}{l}\text { Giannini } 2018 \\
\text { [17] }\end{array}$ & 15 & 0 & 0 & 0 & 0 & 15 \\
\hline & $\begin{array}{l}\text { Howell } 2011 \\
\text { [18] }\end{array}$ & 3 & 0 & 0 & 1 & 0 & 4 \\
\hline & $\begin{array}{l}\text { Karlakki } 2016 \\
\text { [19] }\end{array}$ & 0 & 5 & 4 & 0 & 0 & 9 \\
\hline & $\begin{array}{l}\text { Keeney } 2019 \\
\text { [20] }\end{array}$ & 0 & 4 & 19 & 4 & 0 & 27 \\
\hline & $\begin{array}{l}\text { Manoharan } \\
2016[10]\end{array}$ & 0 & 0 & 1 & 0 & 0 & 1 \\
\hline & $\begin{array}{l}\text { Redfern } 2017 \\
\text { [9] }\end{array}$ & 0 & 9 & 51 & 5 & 13 & 22 \\
\hline
\end{tabular}

\subsubsection{Dressing Changes}

Two studies $[17,19]$ measured the number of the dressing changes. Applying incisional negative pressure wound therapy dressing resulted in fewer dressing changes than conventional wound dressing (MD=-2.00, 95\% Cl -2.24 - -1.76, p < 0.05, Fig. 7).

\subsubsection{Infection Rate}

Three studies $[9,18,20]$ reported the infective events included superficial and deep infection. One study [20] found there was a significant higher rate in late infection after TKA compared with THA $(6.1 \%$ vs $0.9 \%, P=0.03)$. However, there was no clear statistical difference between iNPWT group and control group. Redfern et al [9], reported that the overall rate of infection decreased significantly in iNPWT group compared with control. As for pooled data, there was also no significant difference between the two groups $(R R=0.65$, $95 \% \mathrm{Cl} 0.30-1.40, \mathrm{p}=0.27$, Fig. 8). 


\subsubsection{Rates of Reoperation}

Four studies $[9,18-20]$ reported the reoperation. Redfern et al [9], reported that the number of patients who required reoperation due to complications in each of groups were 3 and 15. Howell et al [18], reported that one patient in each of the two groups had surgical treatment postoperatively due to deep surgical sit infection. Karlakki et al [19], informed of three participants in control group that required surgical treatment again because of postoperative complications. Keeney et al [20], reported that the rates of reoperation in each of groups were $3 / 185$ and $6 / 213$. However, the pooled data did not show significant difference between groups. $(\mathrm{RR}=0.46,95 \% \mathrm{Cl}$ $0.20-1.03, p=0.06$, Fig. 9).

\section{Discussion}

Various strategies of preventing wound complications have already been developed, and the core goal of these strategies is to improve the prognosis and survival qualities of patients with TJA. However, the effect of application of diverse wound dressings remain unclear. Some present studies found that iNPWT has an advantage on wound healing [5,21]. A previous systematic review [22] evaluating the prophylactic use of iNPWT for wound complications in several surgical fields such as laparotomy for abdominal, coronary arteries bypass grafting, and lymphadenectomy. It considered that incisional negative pressure wound therapy dressing seemed to be an effective prophylactic measure in decreasing complications and reoperation rate and be regarded as potentially cost saving especially in high-risk patients. However, there was limited studies on the application of iNPWT in orthopedic surgery. Newman et al [21] conducted a RCT on application of iNPWT compared with silver-impregnated occlusive dressing for revision total hip or knee arthroplasty in patients at high risk for infection. This study found that iNPWT may decrease the rate of postoperative wound complications.

Pachowsky et al [23] conducted a RCT about iNPWT's influence on the development of postoperative seromas in the wound area. The result of this RCT demonstrated that iNPWT may decrease development of postoperative seromas. One cost-effectiveness analysis [24] of iNPWT on primary hip and knee replacements showed that the efficacy of iNPWT in terms of improving cost-effectiveness and comfort for both patients and caregivers was irrefutable. One retrospective study reported that there was significant difference in overall complications between iNPWT and conventional wound dressing. However, the finding was not statistically significant when each individual complication was compared separately[25]. Another study found that iNPWT may increase the Occurrence of blisters, which resulted from trial stopping prematurely [18]. Gillespie et al [11] reported a RCT on iNPWT compared with hydrocolloid dressing for patients undergoing THA. This study found that the iNPWT patients had less surgery site infection indicators but experienced more other postoperative complications and its costs were higher. A systematic review, karlakki et al [26] demonstrated 9 studies reporting the application of iNPWT in orthopedic surgery, five of which were randomized controlled trials (RCTs). Only 3 RCTs involve either THA or TKA. Therefore, there was a lack of high level evidence in the field of adult arthroplasty concerning the application of iNPWT. The benefit of iNPWT after TJA was uncertain.

This meta-analysis including 5 RCTs and 1 prospective cohort study aims to evaluate whether there is difference between iNPWT and conventional wound dressing on wound healing in patients who received TJA. Results from this study showed that applying incisional negative pressure wound therapy dressing may decrease the postoperative dressing changes. It seems to demonstrate that iNPWT may reduce the drainage.

The complications including overall, minor and major were the primary outcome in our study. The occurrence of complications was a sign of wound status, even result in failure of surgery. Our meta-analysis defined complication as minor or major. Some studies indicated that iNPWT had an effect on decreasing complications but there were some studies reporting the opposite efficacy[18, 21, 23]. In this meta-analysis, no difference in overall, minor and major complications were found after TJA.

The rate of infection was also an important outcome in this study. Severe infection was associated with adverse effects including failure of surgery, difficulty of wound healing, and cost. Hence, infection control was desirable. Previous study reported that the iNPWT had less surgery site infection[23]. This was consistent with our study but these differences were no statistically significantly different.

With regard to the rate of reoperation, in our meta-analysis, four included studies reported that the rate of reoperation in iNPWT group was lower[9, 18-20]. However, there were no statistically significant difference. In addition, two included study reported that the reduction in the length of the stay for application of iNPWT, although measurable, was not statistically significant difference.

The limitations of this meta-analysis included that: firstly, there was selection bias in studies $(2 / 5)$, which did not state the method of randomization. The potential bias of selective reporting due to the stopped prematurely may also influenced the true effect measurement. Secondly, the number of included studies and sample sizes in this meta-analysis was small, which may lead to an 
imprecise effect estimation. Finally, subgroup analysis could not be performed for any source of heterogeneity, which may impact the true effect of clinical outcomes.

\section{Conclusions}

For patients with TJA, compared with conventional wound dressing, incisional negative pressure wound therapy dressing may reduce the dressing changes postoperatively. The effect of incisional negative pressure wound therapy dressing on the complications, blistering, reoperation, and infection were uncertain. The effect of incisional negative pressure wound therapy dressing on the length of hospitalization and mortality remains unclear due to insufficient data. Besides, the more expensive cost of incisional negative pressure wound therapy dressing may increase patients' economic burden.

This meta-analysis showed that the current evidence comparing the advantage of these 2 types of dressing is still limited. More prospective randomized controlled trials with high quality are required.

\section{Abbreviations}

iNPWT, incisional negative pressure therapy dressing; CWD, conventional wound dressing; TJA, total joint arthroplasty; RR, risk ratio; TKA, total knee arthroplasty; THA, total hip arthroplasty; RCTs, randomized controlled trials; PCS, prospective cohort studies; BMI, body mass index; $\mathrm{Cl}$, confidence interval; $\mathrm{MD}$, mean differences.

\section{Declarations}

\section{Ethics approval}

Ethical approval is not necessary because it is a comment on previously published articles and does

not involve the handling of any personal patient data.

\section{Consent to publication}

Not applicable

\section{Availability of data and materials}

All data and materials are contained within the manuscript

\section{Competing interests}

The authors declare that they have no competing interests.

\section{Funding}

This study was not supported by any funding.

\section{Authors' contributions}

The following authors designed the study (BS), gathered the data (WXW, MYL), analyzed the data (WXW, YL), wrote the initial drafts (WXW), and ensured the accuracy of the data and analysis (BS, YZ, YGW). All authors have read and approved the manuscript

\section{Acknowledgement}

Not applicable

\section{Authors' information}

Wen-Xing Wei", MD, Yi Zeng ,MD, Yuan Liu, MD, Ming-Yang Li, MD, Yuan-gang Wu, MD, Bin Shen ${ }^{\star}, M D$, PhD.

Department of Orthopaedic Surgery, West China Hospital,, Sichuan University, Chengdu, Sichuan Province, China 610041 


\section{References}

1. Kamaruzaman $\mathrm{H}$, Kinghorn $\mathrm{P}$, Oppong R: Costeffectiveness of surgical interventions for the management of osteoarthritis: a systematic review of the literature. BMC Musculoskelet Disord 2017, 18(1):183.

2. Mangram A, Horan TC Guideline for Prevention of Surgical Site Infection, 1999. Centers for Disease Control and Prevention (CDC) Hospital Infection Control Practices Advisory Committee.. Am J Infect Control 1999:27(22):97-132; quiz 133-134; discussion 196.

3. Siqueira MB, Ramanathan D, Klika AK, Higuera CA, Barsoum WK: Role of negative pressure wound therapy in total hip and knee arthroplasty. World journal of orthopedics 2016, 7(1):30-37.

4. Glass GE, Murphy GF, Esmaeili A, Lai LM, Nanchahal J: Systematic review of molecular mechanism of action of negative-pressure wound therapy. The British journal of surgery 2014, 101(13):1627-1636.

5. Huang C, Leavitt T, Bayer LR, Orgill DP: Effect of negative pressure wound therapy on wound healing. Current problems in surgery 2014, 51(7):301-331.

6. Moues $\mathrm{CM}$, van den Bemd GJ, Heule F, Hovius SE: Comparing conventional gauze therapy to vacuum-assisted closure wound therapy: a prospective randomised trial. Journal of plastic, reconstructive \& aesthetic surgery : JPRAS 2007, 60(6):672-681.

7. Stannard JP, Robinson JT, Anderson ER, McGwin G, Jr., Volgas DA, Alonso JE: Negative pressure wound therapy to treat hematomas and surgical incisions following high-energy trauma. J Trauma 2006, 60(6):1301-1306.

8. Stannard JP, Singanamala N, Volgas DA: Fix and flap in the era of vacuum suction devices: What do we know in terms of evidence based medicine? Injury 2010, 41(8):780-786.

9. Redfern RE, Cameron-Ruetz C, O'Drobinak SK, Chen JT, Beer KJ: Closed Incision Negative Pressure Therapy Effects on Postoperative Infection and Surgical Site Complication After Total Hip and Knee Arthroplasty. The Journal of arthroplasty 2017, 32(11):3333-3339.

10. Manoharan V GALHACHKWMPMPJ: Closed Incision Negative Pressure Wound Therapy vs Conventional Dry Dressings After Primary Knee Arthroplasty: a Randomized Controlled Study. Journal of arthroplasty 2016, 31(11):2487.

11. Gillespie Bm RCMTLKEFTHALGPDCW: Use of Negative-Pressure Wound Dressings to Prevent Surgical Site Complications After Primary Hip Arthroplasty: a Pilot RCT. Surgical innovation 2015, 22(5):488.

12. Moher D, Liberati A, Tetzlaff J, Altman DG: Preferred reporting items for systematic reviews and meta-analyses: the PRISMA statement. Journal of clinical epidemiology 2009, 62(10):1006-1012.

13. Borzio RW, Pivec R, Kapadia BH, Jauregui JJ, Maheshwari AV: Barbed sutures in total hip and knee arthroplasty: what is the evidence? A meta-analysis. International orthopaedics 2016, 40(2):225-231.

14. Higgins J, Green S: Cochrane Handbook for Systematic Reviews of Interventions Version 5.1.0 [updated March 2011] The Cochrane Collaboration 2011

15. Jadad AR, Moore Ra Fau - Carroll D, Carroll D Fau - Jenkinson C, Jenkinson C Fau - Reynolds DJ, Reynolds Dj Fau - Gavaghan DJ, Gavaghan Dj Fau - McQuay HJ, McQuay HJ: Assessing the quality of reports of randomized clinical trials: is blinding necessary? (0197-2456 (Print))

16. F. Chuling HH, X. Zuojun, : The Newcastle-Ottawa Scale (NOS) for Assessing the Quality of Nonrandomized Studies. 2016.

17. Giannini S MALDLGTGAICMFC: Postoperative wound management with negative pressure wound therapy in knee and hip surgery: a randomised control trial. Journal of wound care 2018, 27(8):520.

18. Howell RD, Hadley S, Strauss E, Pelham FR: Blister formation with negative pressure dressings after total knee arthroplasty. Current Orthopaedic Practice 2011, 22(2):176-179.

19. Karlakki SL, Hamad AK, Whittall C, Graham NM, Banerjee RD, Kuiper JH: Incisional negative pressure wound therapy dressings (iNPWTd) in routine primary hip and knee arthroplasties: A randomised controlled trial. Bone \& joint research 2016, 5(8):328-337.

20. Keeney JA, Cook JL, Clawson SW, Aggarwal A, Stannard JP: Incisional Negative Pressure Wound Therapy Devices Improve ShortTerm Wound Complications, but Not Long-Term Infection Rate Following Hip and Knee Arthroplasty. Journal of Arthroplasty 2019.

21. Newman JM, Siqueira MBP, Klika AK, Molloy RM, Barsoum WK, Higuera CA: Use of Closed Incisional Negative Pressure Wound Therapy After Revision Total Hip and Knee Arthroplasty in Patients at High Risk for Infection: A Prospective, Randomized Clinical Trial. Journal of Arthroplasty 2019, 34(3):554.

22. Scalise A, Calamita R, Tartaglione C, Pierangeli M, Bolletta E, Gioacchini M, Gesuita R, Benedetto GD: Improving wound healing and preventing surgical site complications of closed surgical incisions: A possible role of incisional negative pressure wound therapy. A 
systematic review of the literature. International wound journa/ 2016, 13(6):1260-1281.

23. Pachowsky M GJKALSS-DSSPPJGKBMH: Negative pressure wound therapy to prevent seromas and treat surgical incisions after total hip arthroplasty. International orthopaedics 2012, 36(4):719.

24. Nherera LM, Trueman P, Karlakki SL: Cost-effectiveness analysis of single-use negative pressure wound therapy dressings (sNPWT) to reduce surgical site complications (SSC) in routine primary hip and knee replacements. Wound repair and regeneration : official publication of the Wound Healing Society [and] the European Tissue Repair Society 2017, 25(3):474-482.

25. Curley AJ, Terhune EB, Velott AT, Argintar EH: Outcomes of Prophylactic Negative Pressure Wound Therapy in Knee Arthroplasty. Orthopedics 2018, 41(6):e837-e840.

26. Karlakki S, Brem M, Giannini S, Khanduja V, Stannard J, Martin R: Negative pressure wound therapy for managementof the surgical incision in orthopaedic surgery: A review of evidence and mechanisms for an emerging indication. Bone \& joint research 2013, 2(12):276-284.

\section{Figures}

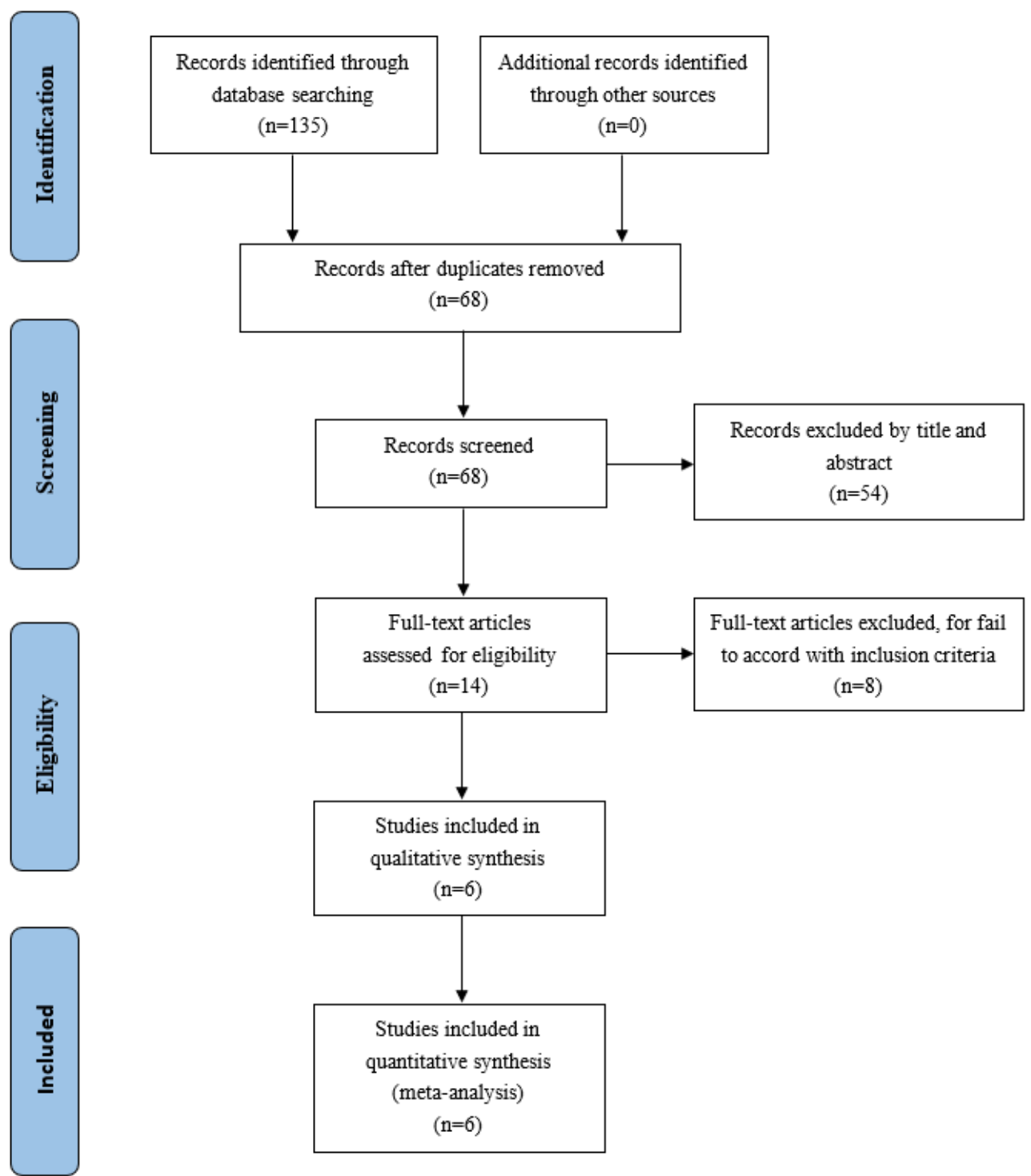

Figure 1

Flowchart of inclusion and exclusion for eligible studies. 


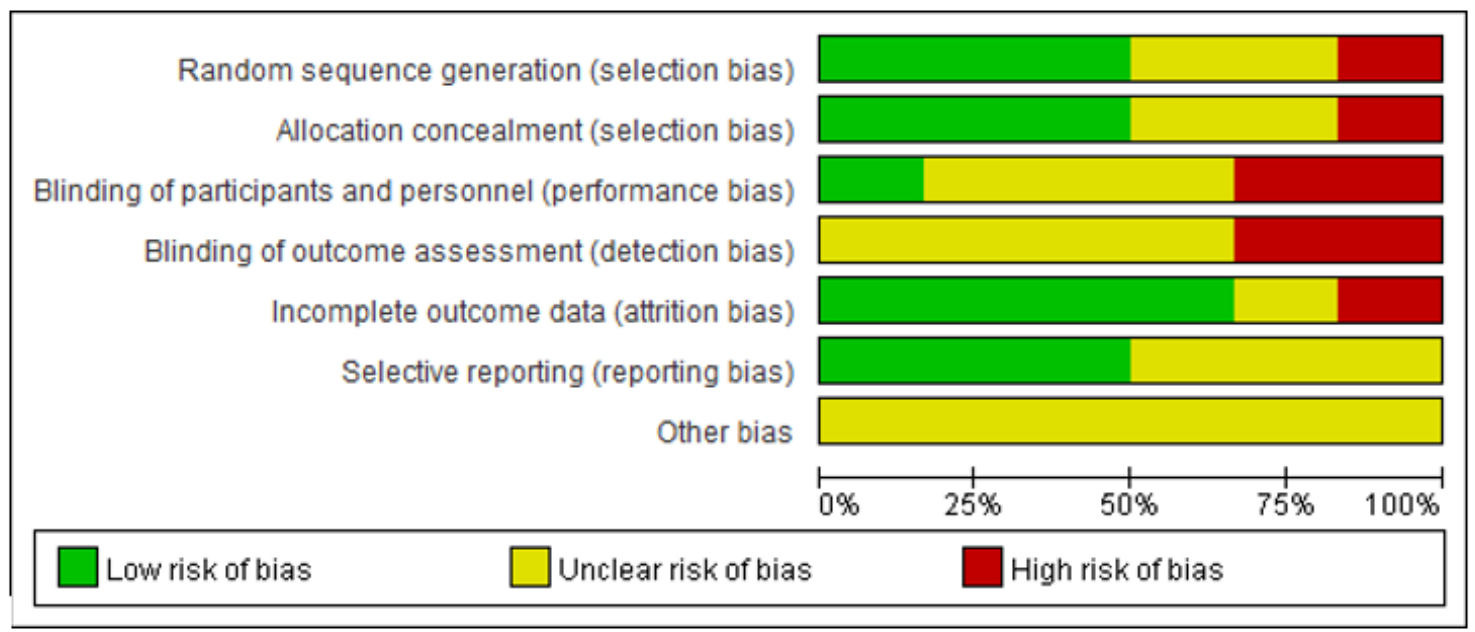

\section{Figure 2}

Risk of bias assessment of included studies.

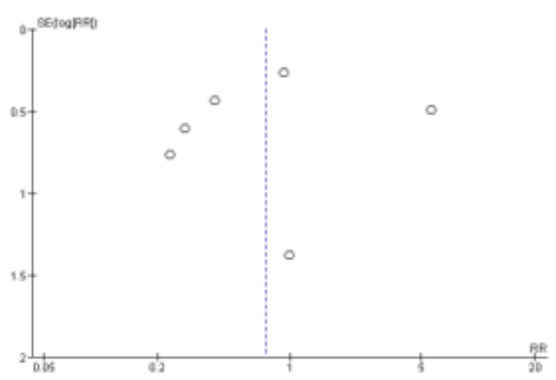

a)

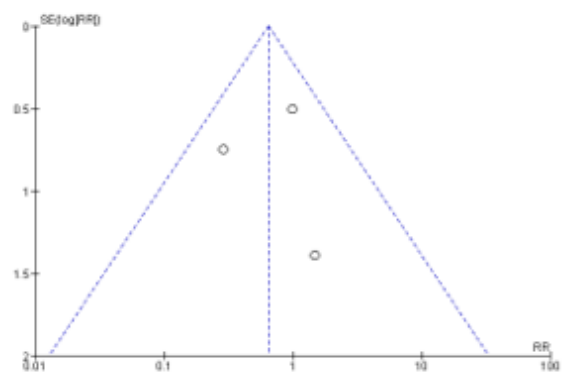

d)

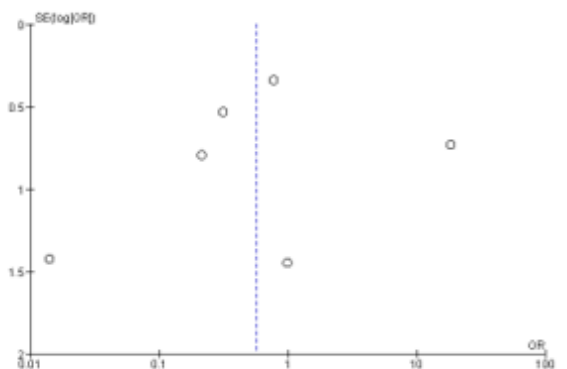

b)

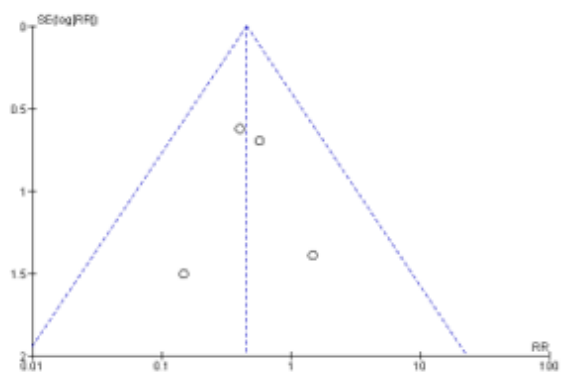

e)

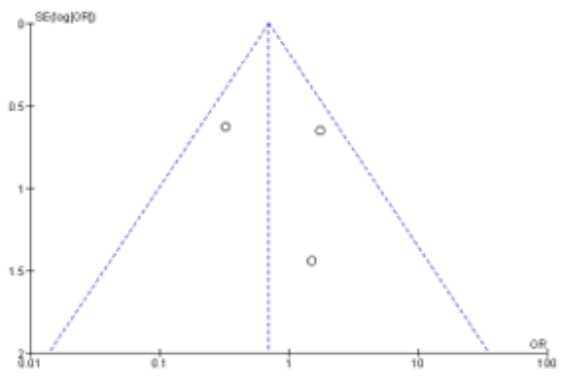

C)

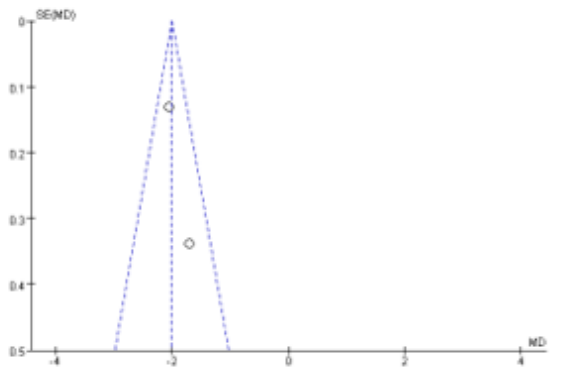

f)

\section{Figure 3}

Funnel plot. (a) A funnel plot of overall complications; (b) A funnel plot of minor complications; (c) A funnel plot of major complications; (d) A funnel plot of the rate of infection; (e) A funnel plot of the rate of reoperation; (f) A funnel plot of the number of dressing changes. 


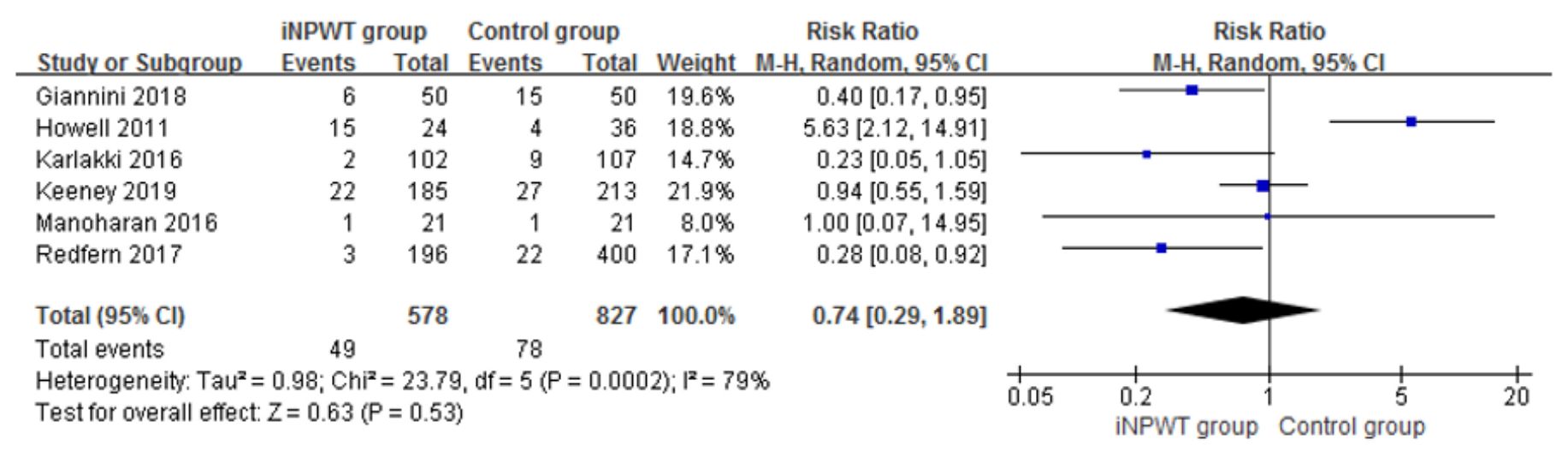

Figure 4

The overall complications forest plot analysis.

\begin{tabular}{|c|c|c|c|c|c|c|c|c|c|c|}
\hline \multirow[b]{2}{*}{ Study or Subqroup } & \multicolumn{2}{|c|}{ iNPWT group } & \multicolumn{2}{|c|}{ Control group } & \multicolumn{3}{|c|}{ Odds Ratio } & \multirow{2}{*}{\multicolumn{2}{|c|}{$\begin{array}{c}\text { Odds Ratio } \\
\text { M- } \mathrm{H} \text {, Random, } 95 \% \mathrm{Cl}\end{array}$}} & \\
\hline & Events & Total & Events & Total & Weight & M-H, Random, $95 \% \mathrm{Cl}$ & & & & \\
\hline Giannini 2018 & 6 & 50 & 15 & 50 & $19.5 \%$ & $0.32[0.11,0.91]$ & & & & \\
\hline Howell 2011 & 15 & 24 & 3 & 36 & $17.9 \%$ & $18.33[4.33,77.55]$ & & & & \\
\hline Karlakki 2016 & 2 & 102 & 9 & 107 & $17.5 \%$ & $0.22[0.05,1.03]$ & & & & \\
\hline Keeney 2019 & 16 & 185 & 23 & 213 & $20.6 \%$ & $0.78[0.40,1.53]$ & & & & \\
\hline Manoharan 2016 & 1 & 21 & 1 & 21 & $12.1 \%$ & $1.00[0.06,17.12]$ & & & & \\
\hline Redfern 2017 & 0 & 196 & 60 & 400 & $12.3 \%$ & $0.01[0.00,0.23]$ & $4-$ & & & \\
\hline Total $(95 \% \mathrm{Cl})$ & & 578 & & 827 & $100.0 \%$ & $0.58[0.13,2.61]$ & & & & \\
\hline Total events & 40 & & 111 & & & & & & & \\
\hline $\begin{array}{l}\text { Heterogeneity: Tau² } \\
\text { Test for overall effect }\end{array}$ & $\begin{array}{l}2.72 ; \mathrm{Chi} \\
\mathrm{Z}=0.71\end{array}$ & $\begin{array}{l}=34.63 \\
=0.48)\end{array}$ & $\mathrm{df}=5$ & $<0.000$ & $101) ;\left.\right|^{2}=8$ & $6 \%$ & 0.01 & $\begin{array}{l}0.1 \\
\text { iNPWT group }\end{array}$ & 10 & 100 \\
\hline
\end{tabular}

\section{Figure 5}

The minor complications forest plot analysis.

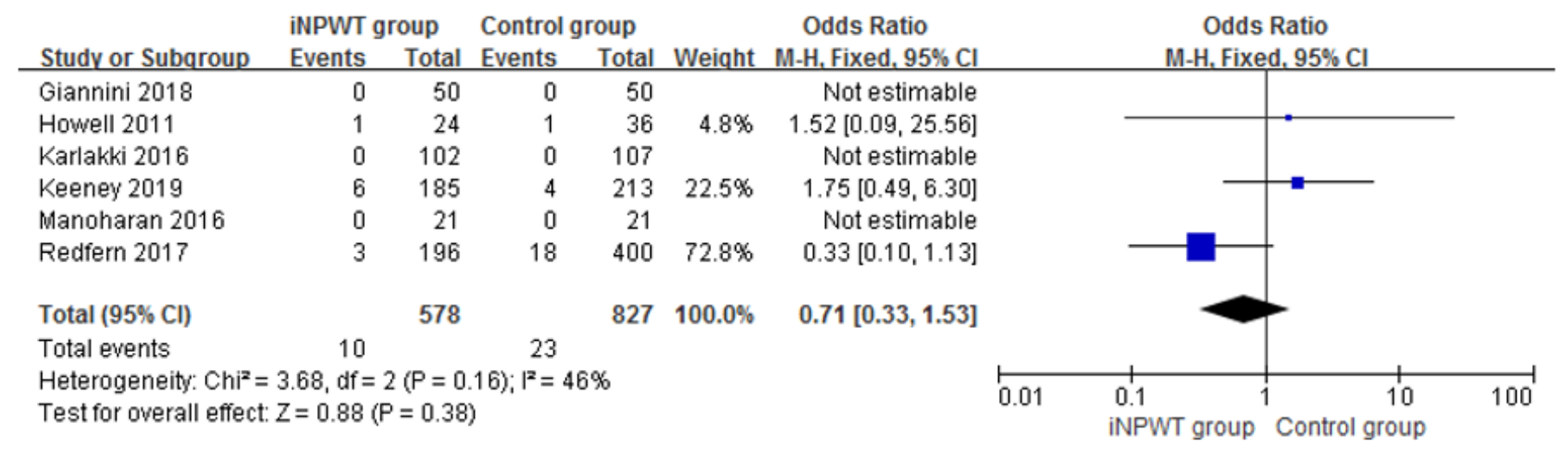

Figure 6

The major complications forest plot analysis. 


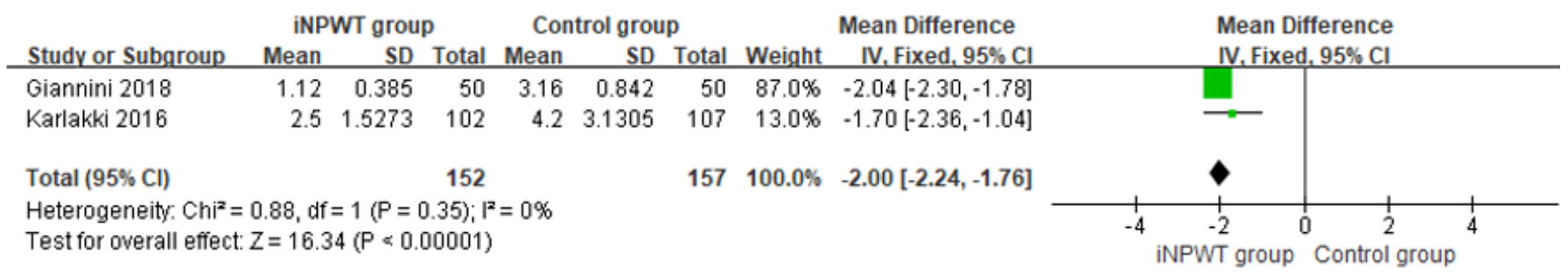

\section{Figure 7}

The dressing changes forest plot analysis.

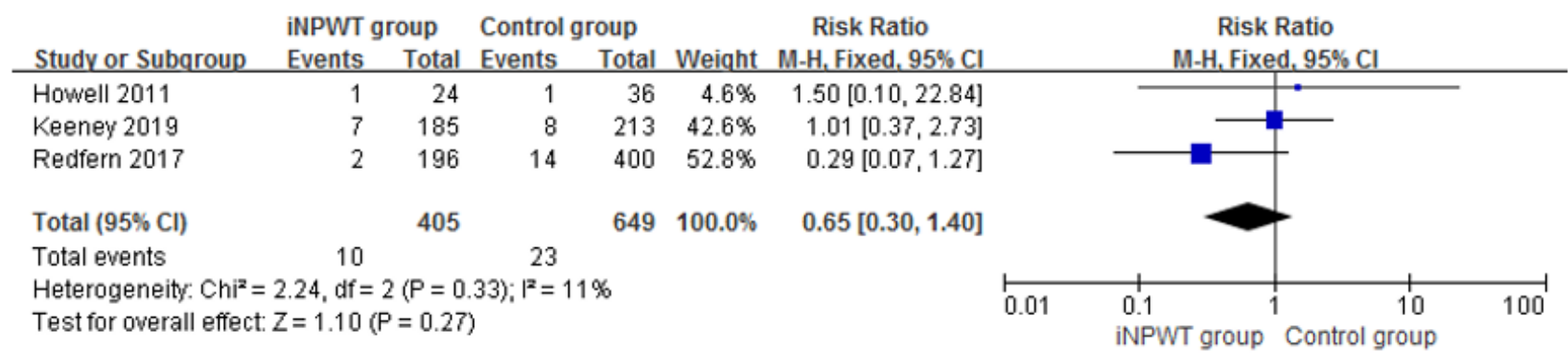

\section{Figure 8}

The rate of infection forest plot analysis.

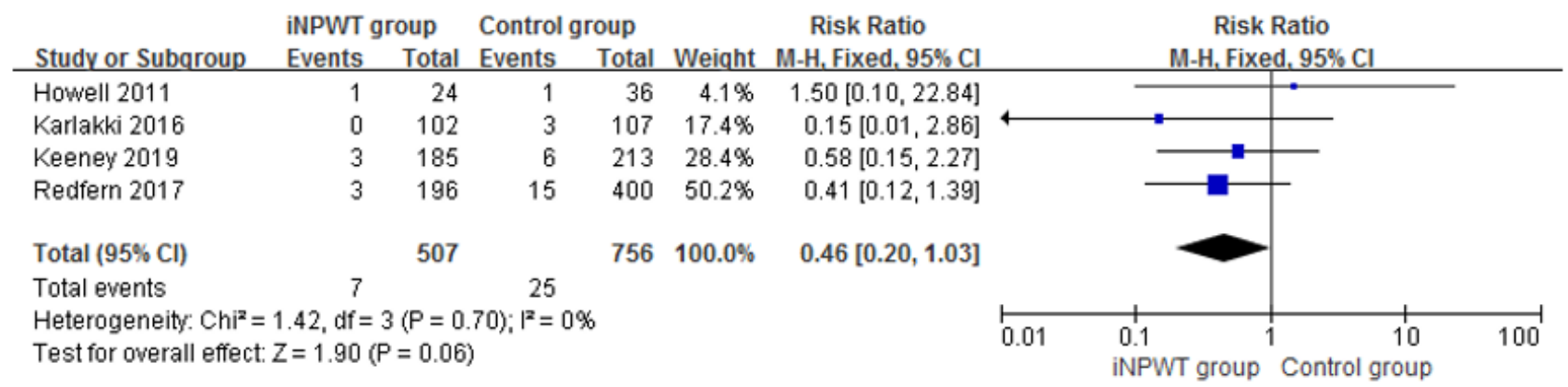

\section{Figure 9}

The rates of reoperation forest plot analysis.

\section{Supplementary Files}

This is a list of supplementary files associated with this preprint. Click to download.

- PRISMAchecklist.doc 